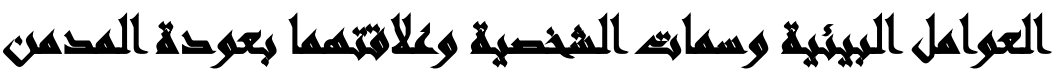

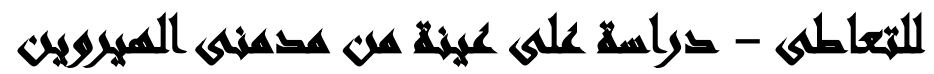

\section{$[1 \cdot]$}

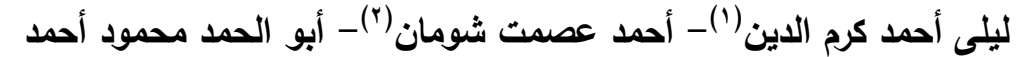

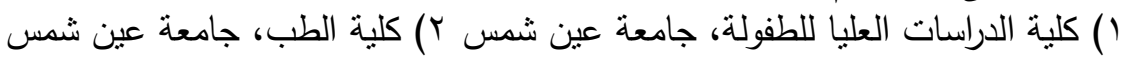

\section{المستخليف}

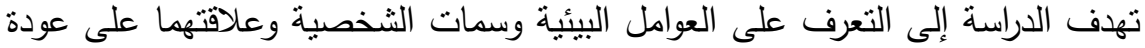

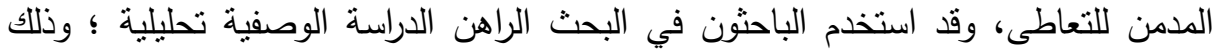

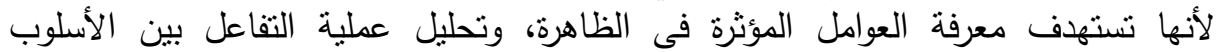

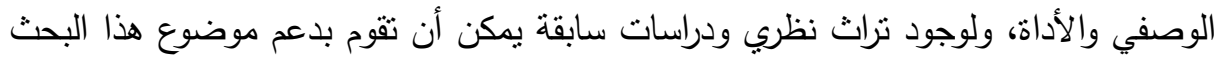
الذي مازال يحتاج إلى العديد والعديد من الدراسات.

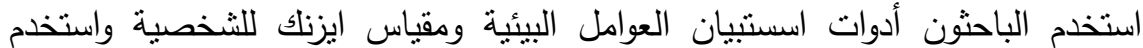

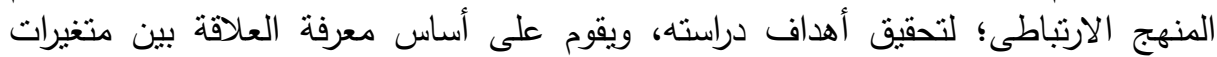

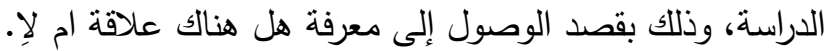

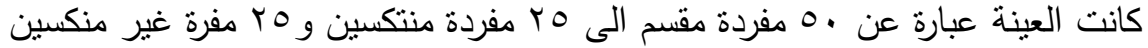

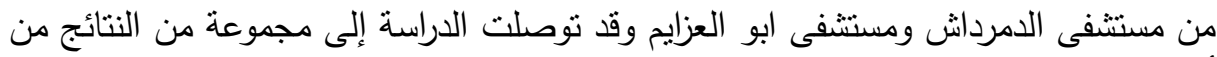

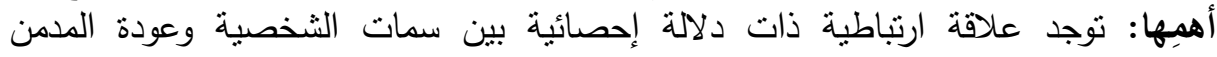
للهيروين، كما توجد فروق ذات دلالة إحصائية بين عينة الدراسة (المنتكسين وغير المنتكسين) الكلمات المفتاحية: العوامل البيئية - سمات الثخصية - الانتكاسة.

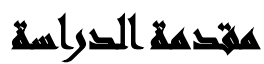

تعد مشكلة الادمان مشكلة عالمية حيث تعانى منها معظم دول العالم كما تعانى منها مصر كما يعانوا من تتامى وتعاظم مشكلة استعمال المخدرات والكحوليات وتعد مشكلة الاعتماد على المواد المخدرة من أخطر المشاكل التى تواجه المجتمع حيث تؤثر على الثباب فى مرحلة حرجة من حياتهم، كما تؤثر على البالغين بشكل يؤدى لخفض الانتاجية وغياب

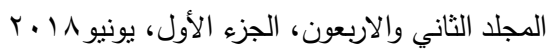


الاستقرار الاجتماعى والاقتصادى، والانحراف السلوكى عن معايير المجتمع، بالاضافة الى انتشار الجريمة والاتحلال الجسدى والاخلافى فى شريحة كبيرة من شرائح المجتمع.

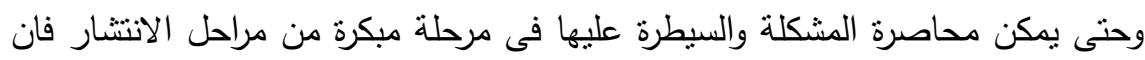

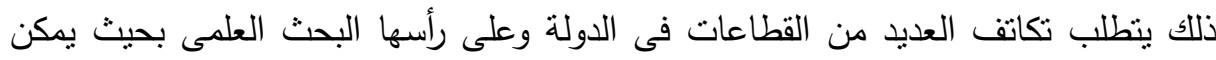
توفير قاعدة بيانات موتقة بمكن من خلالها رسم الاستراتيجة المناسبة للتعامل مع المشكلة، لهنه

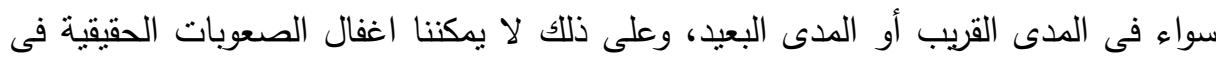

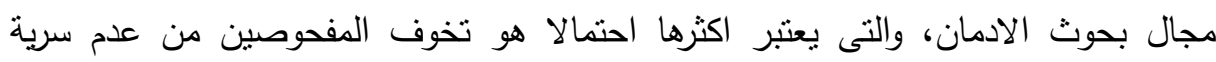

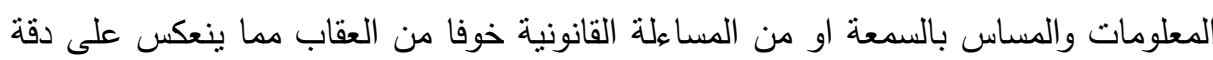
البيانات التى يتم الحصول عليها من العينة محل الدراسة. كما أن الأضرار الواقعة على الصحة الجسمانية والنفسية والاجتماعية والاقتصادية

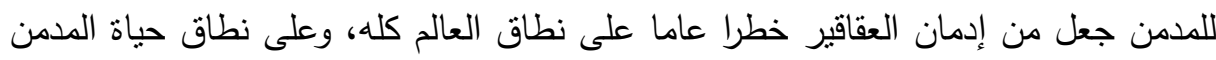

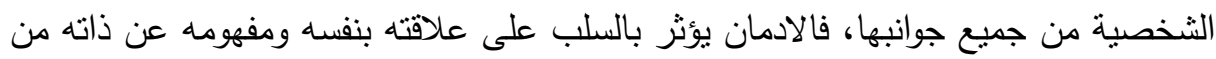
حيث تحديد اهدافة واهتماماته ورسم الخطط المستقبلية والتطلع الى المستقبل، كما يمس الصلة بالبيئة التى يعيش فيها من خلال علاقته بافراد اسرته وعلاقته بالمجتمع الذى يعيش فيه.

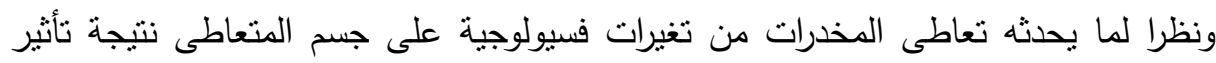

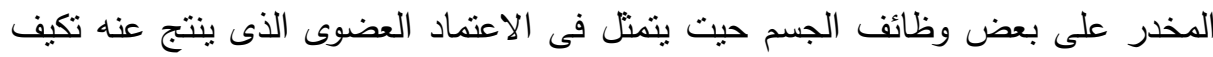

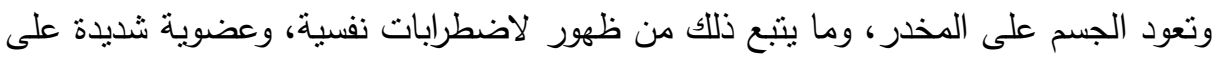

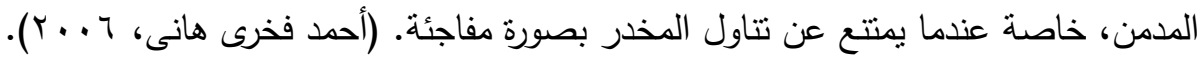




\section{مهوحلة التراسمة}

إذا نظرنا الى خطر الادمان وسوء استخدام العقاقير، نجد هذا الوباء الددمر يتمثل فى

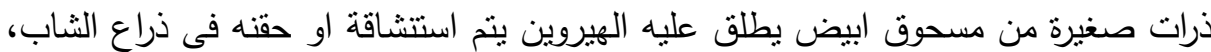
أو دخان سموم يتصاعد من سيجارة او غليون أو نرجيلة أو حبة يبتلعها الثاب اعتقادا منه

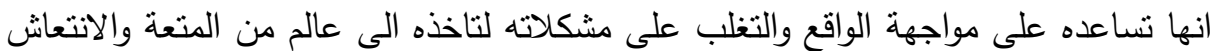
الوهمى الذى سرعان مايفيق من عالمه الخيالى منه ليصطدم مرة أخرى بواقعه المرير ليجد تفاقم العديد من المشكلات على راسه نتيجة للهروب من مواجهتها والتعامل معها، وبهذا نجد إن شريحة هامة من شرائح المجتمع متمثلة فى شبابه ينحدرون الى الهاوية أخذين معهم آمال

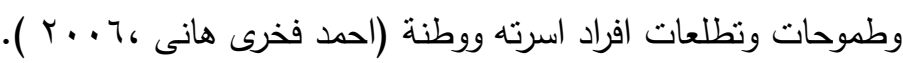

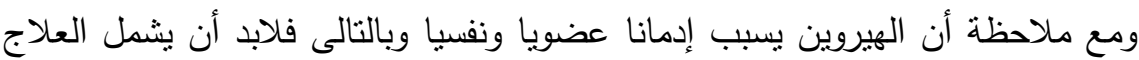

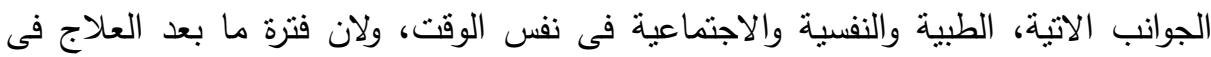

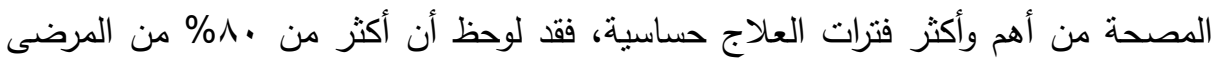

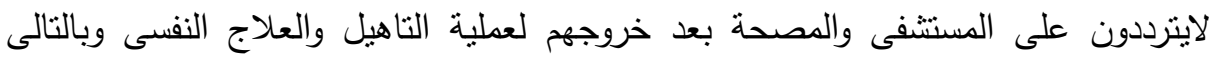
يكون المريض اكثر عرضة للنكسات بسبب عوامل عده، (جمال ماضى ابو العزايم، 911 (1). ويلاحظ ارتفاع نسبة العائدين الى ادمان الهيروين بعد علاجهم حيث تصل حلات العودة

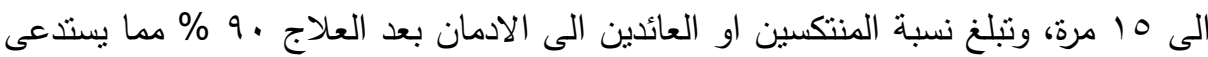

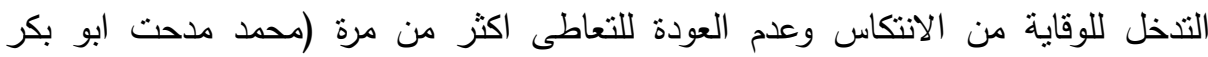

ولذلك ترى عطيات ناثد ان التاهيل عملية ديناميكية متكاملة تهدف الى استثمار قدرات الفرد وطاقاته الى اقصاها لاكتساب انسب المهارات المهنية ليتمكن بها من المعايشة الاستقإلية وعلى درجة مناسبة من التوافق الاجتماعى، (عطيات ناثند واخرون ، 1999 ) ). 


\section{أهساهنش التراسة}

• الوقوف على العلاقة بين العوامل البيئية وسمات الشخصبة من جهة وعودة المدمن للتعاطى من جهة اخرى. • تحديد تاثير العوامل البيئية على عملية تاهيل المدمن. • تحديد تاثير سمات الثخصية على عملية تاهيل المدمن. • معرفة امكانية الاستفادة من وجود علاقة بين العوامل البيئية وسمات الشخصية من جهة وعودة المدمن للتعاطى من جهة اخرى. • محاولة الحد من الانتكاسة او العودة للتعاطى

\section{هزوضر التراسما}

تتحدد فروض الدراسة في النقاط التإلية: • توجد علاقة ارتباطية ذات دلالة إحصائية بين سمات الثخصية وعودة مدمن للهيروين • توجد فروق ذات دلالة إحصائية بين عينة الدراسة (المنتكسين وغير المنتكسين) لسمات

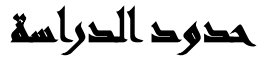

تتمثل حدود الاراسة فيما يلي: الحدود المكانيـة: بعض مصحات وبيوت تأهيل مرضى ادمان الهيروين بمحافظة القاهرة وقد حدد الباحثون المراكز العلاجية والمصحات الموجودة بالمحافظة والمسجلة قانونا بالجهات التـى حددها القانون والتابعـة لوزارة الصـحة والسكان سـواء كانـت حكوميـة او خاصــة وكـان تعدادها r r منشـأة مسـجلة رسميا بـالمجلس القومى للصـحة النفسية وبـالعلاج الحر بـوزارة الصحة وتخير منها الباحث مستشفى الدمرداش للصحة النفسية ومستتفى ابوالعزايم للطب لعبد النفسى. 
الحدود البشرية: عينة من مدمنى مخدر الهيروين الراثدين فوق 1 ا عام ممثلة من الفئات التى تدمن مخدر الهيروين وتم تقسيمهم إلى منتكسين وغير منتكسين. الحدود الزمنية: قام الباحثون بجمع الاسس النظرية للاراسة والاطلاع على الدراسات السابقة ودراسـة العناصر التى لم نتتاولها تلك الدراسات ثم لعمل على الجانب التطبيقى فى البحث

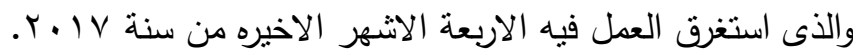

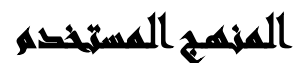

المنهج وصفى يعتمد على دراسة الظاهرة كما توجد فى الواقع، بوصفها وصفا دقيقا ويعبر عنها كيفيا او تعبيرا كميا، فالتعبير الكيفى يصف لنا الظاهرة ويوضح خصائصها اما التعبير الكمى فعيطينا وصفا رقميا يوضح مقدار هذه الظاهرة او حجمها ودرجات ارتباطية مع الظواهر المختلفة الاخرى ولكن كلاهما مرتبط منذ نشأته بدراسة المشكلات المتعلقة بالمجالات الانسانية ومازال هذا هو الاكثر استخداما فى الدراسات الانسانية حتى الان، ويعتبر المنهج الوصفى التحليلى اكثر المناهج السائدة فى البحوث التى تعنى بدراسة مشاكل العلوم الانسانية

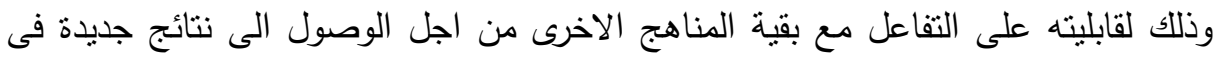
هذه المجالات العلمية الهامة. (امين ساعاتى، (99 (19).

\section{أهمية التصراسلة}

• وجود مشكلة يجمع عليها العلماء وحتى العامة تتعلق بتعاطى وتجارة المخدرات.

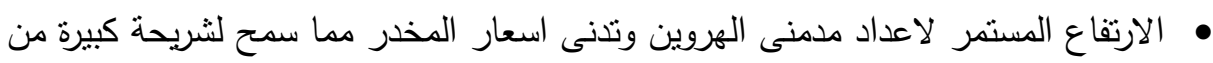
المجتمع باستخدامه دون العلم بخطورته. • ضرورة الاهتمام بعملية اعادة تأهيل المدمن كمرحلة اساسية ومهمة لمنع الانتكاسة او العودة الى تعاطى الهيروين. • دراسة العوامل البيئية وسمات الثخصية والاجابة عن السؤال عما اذا كان لهما علاقة

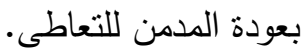


• محاولة تقديم جهد من اجل المساعدة على تقليل الظاهرة والحد من انتشارها. • انفاق اموال طائلة فى عملية جلب وتهريب وتعاطى ومكافحة المخدرات فى وقت اصني اصنى

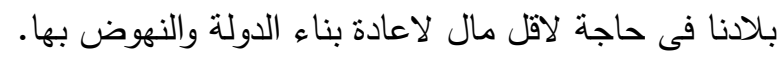
• يمكن تتاول متغيرات هذه الدراسة معا فى ادبيات علم النفس.

\section{مخاسهيم القراسما}

تحتوى الدراسة على عدد من المفاهيم، وهي على النحو التإلي: 1 - مفهوم المخدرات: هى مجموعة من العقاقير التى تؤثز على النشاط الذهنى والحالة النفسية لمتعاطيها اما بتنشيط الجهاز العصبى او بابطاء نشاطه، من خلال الدخول فى التركيب البيولوجى للجسم او بما يؤدى الى مشكلات اجتماعية متعددة وضارة تتعكس اثارها على الفرد والاسرة والمجتع ،كما ينظر إليها على انها مجموعة من المواد التى تسبب الادمان، وتسمم الجهاز العصبى ويحذر تداولها او زراعتها او تصنيعها الا لاغراض علاجية يحددها القانون، ولا نستعمل الا بواسطة من يرخص له بذلك، وتتشمل هذه المواد

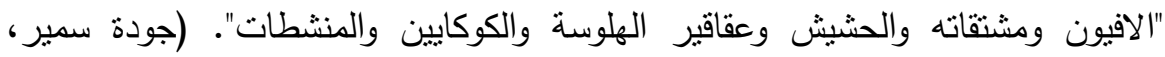

r - الادمان: هو سلوك يدفع الفرد الى رغبة عارمة وملحة وحاجة غالبة للاستمرار فى تعاطى المخدر، واحساسات جسيمة تتجم عن اعتماد البدن على التعاطى، بحيث لو حرم منها نظهر عليه اعراض معينة من الالم الجسمانى والعصبى ومتلكه مثل من يحرم من

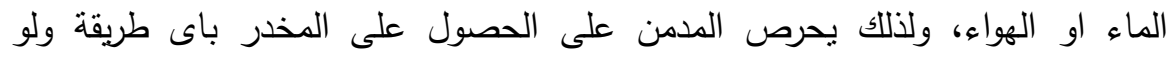

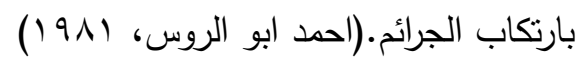

r- مفهوم المدمن: ويعرف على انه شخص معوق ويحتاج الى تاهيل حيث ان المعوق هو كل فرد يختلف عن الثخص السوى من النواحى الجسمية او العقلية او المزاجية او الاجتماعية، الى الدرجة التى تستوجب عمليات التاهيل الخاصة، حتى يصل الى استخدام

$$
\text { اقصى ما تسمح به قدراته ومواهبه. (عطيات ناشد واخرون، } 997 \text { (1). }
$$


צ - مفهوم الهيروين: الهيروين هو ذلك العقار المصنع (المشتق) من الافيون او المورفين بعملة كيميائية تسمى (الاستلة) ويعرف كيميائيا بثانى خلات المورفين، والهيروين من حيث الناثير يندرج تحت انواع المواد المخدرة التى تبطئ من النشاط الذهنى وقوته تتراوح

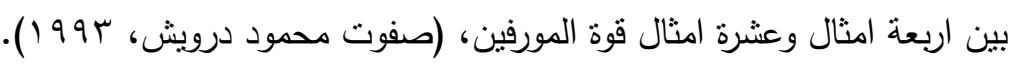
ه- مفهوم السمات الشخصة: (Personality): والشخصية كمصطلح يعنى برسونالتى باللغة الانجليزية، وهو مصطلح لاتينى مشتق من كلمة برسونا وهى القناع، ويعود استعمالها الى زمن الاغريق عندما كان الممنل المسرحى يضع القناع على وجهه عند اداءه لدور شخصيات معينة بهدف ايضاح الصفات المميزة التى يتطلبها ذلك الدور

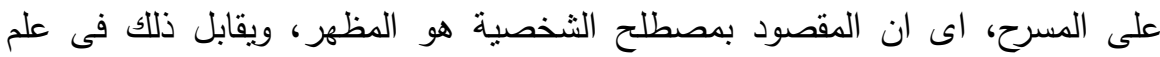
النفس الحديث، السلوك الذى يتفق مع القيام بدور معين(Kala , 1990).

צ- الانتكاسة: هى عودة المدمن المتعافى الى الاعتماد على المواد المخدرة بعد التعافى اى استعمال هذه المواد مره اخرى ،اى بعد نجاحه فى الانقطاع عن استعمالها لفترة

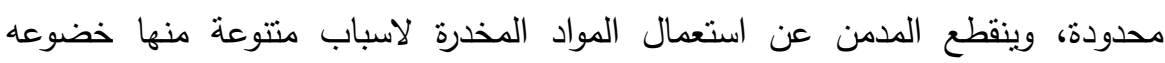
للعلاج او يجبر على نركها نتيجة ظروف خارجية، بسبب انتقاله الى بيئة جديدة لا تتوافر

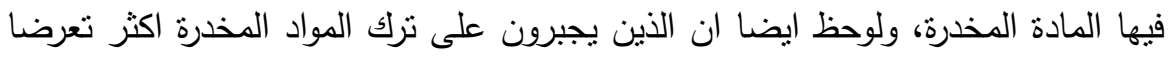

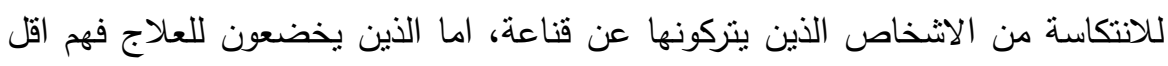
عرضة للانتكاسة من الذين يتركون المخدرات بانفسهم دون مساعدة طبية، ويتتاقص باتهن

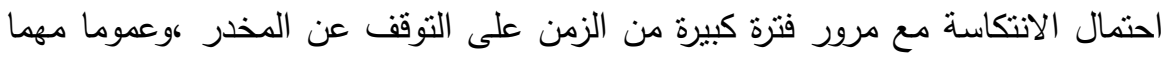

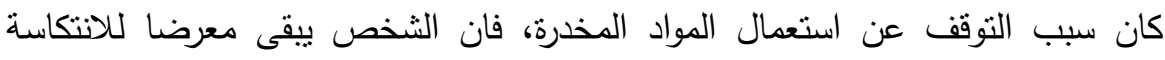

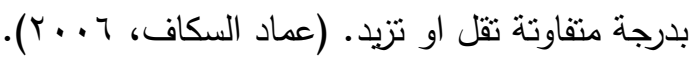

ا- تعريف البيئة: بطلق العلماء لفظ البيئة على مجموعة الظروف والعوامل الخارجية التى تعيش فيها الكائنات الحية وتؤثز فى العمليات الحيوية التنقوم بها، ويقصد بالنظام البيع أية مساحة من الطبيعة وما تحوية من كائنات حية ومواد غير حية فى تفاعلها مع بعضها

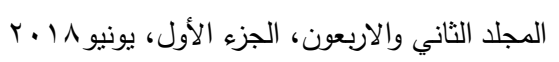


البعض ومع الظروف البيئية وما تولده من تبادل بين الاجزاء الحية وغير الحية، ومن

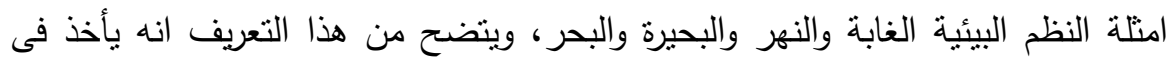

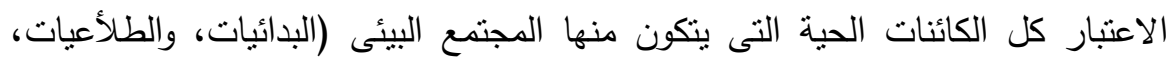

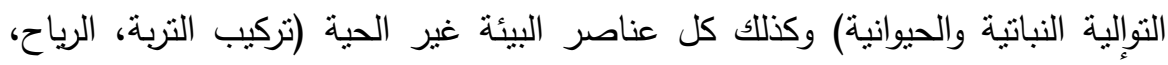

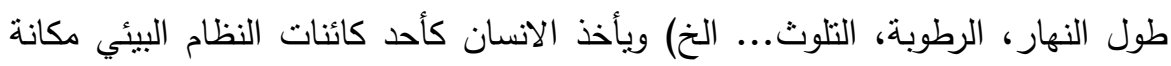
خاصة نظرا لتطوره الفكرى والنفسى، فهو المسيطر الى حد ملموس على النظام البيئى وعلى حسن تصرفه نتوقف المحافظة على النظام البيئي وعدم استتزافه. (تامر اسماعيل

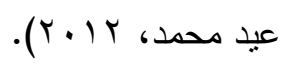

r- تعريف العوامل البيئية: وقد قسم العلماء العوامل البيئية الى قسمين رئيسين هما:

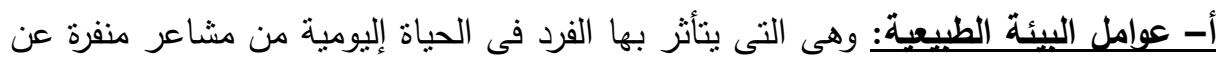
طريق مثيرات خارجية مثل (حرارة، رطوبة، ضوضاء، ازدحام، موصلات، الدخان،.... الخ) والتى تؤثز عليه بالسلب وتنساهم فى ايجاد دوافع عدوانيه لديه. ب- عوامل الييئة الاجتماعية: هى مجموعة من العوامل ذات الطابع الاجتماعى مثل بيئة

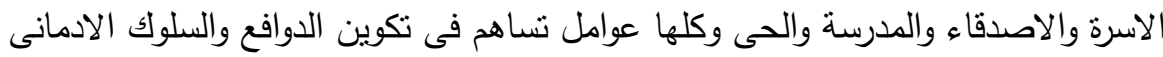
لاى احد افراد المجتمع او هى التى تتشأ اساسا من العلاقات الاجتماعية السائدة فى والى

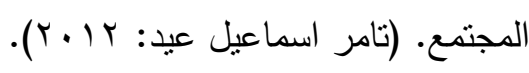

\section{السراسايه المايرية}

يعرض الباحثون بعض أسهامات الدراسات السابقه فى مجال نتاول المخدرات والعوامل الفيزيقية وسمات الثخصية والانتكاسة. دراسة (محمد حسين الحسينى Y Y ب Y): نتاولت هذه الدراسة عرضا لبعض المتغيرات النفسية المرتبطة بتعاطى المخدرات والمتمنلة فى تقدير الذات والمساندة الاجتماعية والتوافق النفسى، مع عرض لبرنامج علاجى بالسيكو دراما، ومحاولة لاثبات مدى فاعلية هذا البرنامج من خلال التطبيق. 
استخدم الباحث المنهج الاكلينيكى، وقام الباحث بتطبيق الاختبار الاسقاطى "تفهم الموضوع" بالاضافة الى الادوات السيكومترية (اختبار تقدير الذات، واختبار المساندة

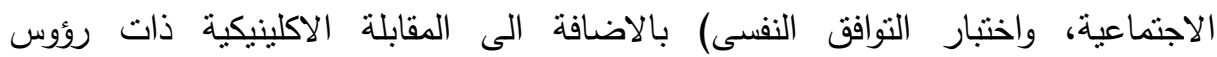

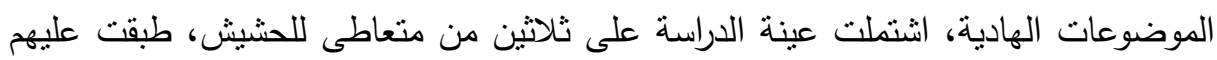

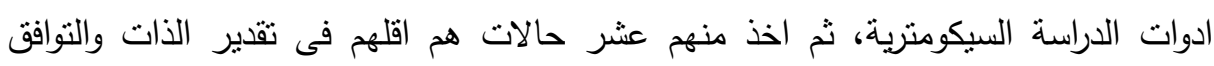

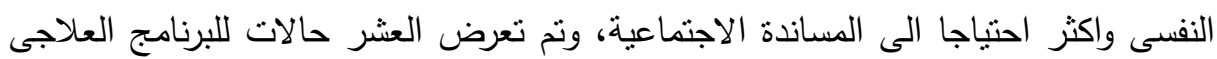
بالسيكودراما، تم استخدام معادلة ولكوكسون، حيث انها تصلح للعينات الصغيرة.

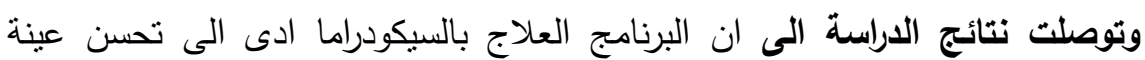

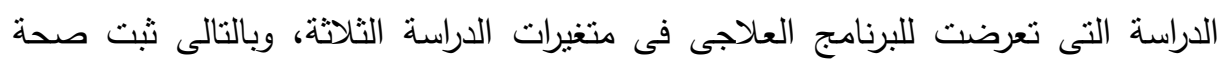

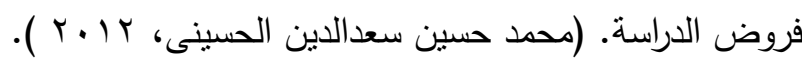

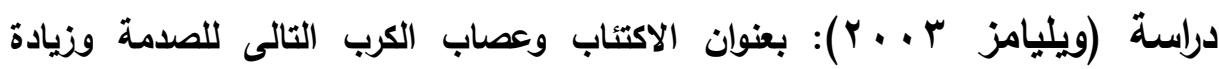

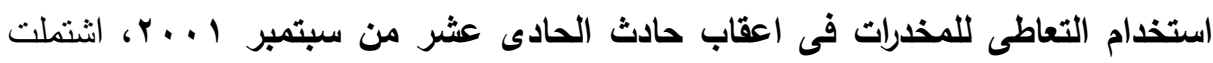

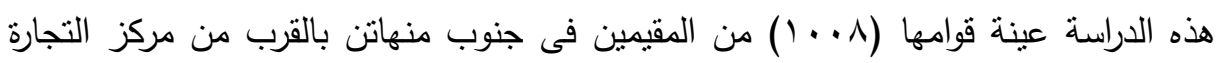

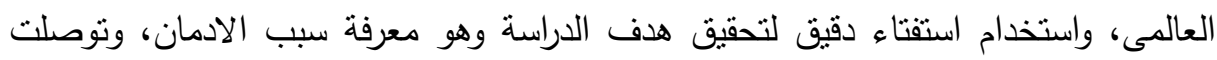

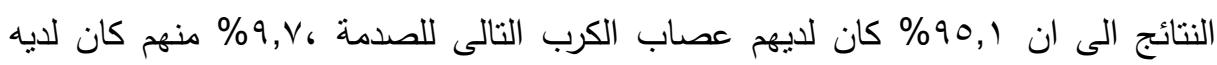
اعلااض اكتئاب ،ووجدت الدراسة ان r, اءع\% من العينة كانوا يدخنون السجائر فاصبحوا

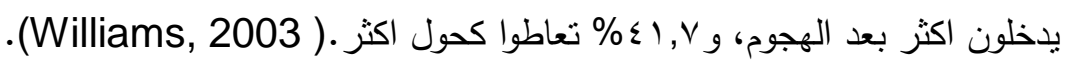

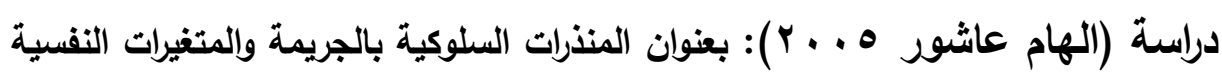

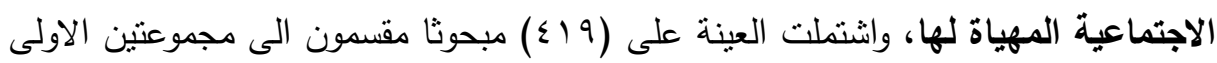

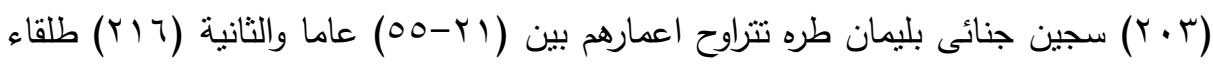
تراوحت اعمارهم بين (TV-IV) عاما، وتوصلت الى وجود ستة عوامل للمنذرات السلوكية

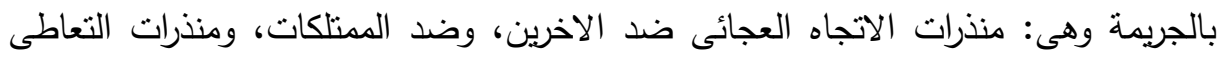
والادمان والارتشاء والنتاجر مع الاسرة، والمراوغة والتهرب من الالتزمات. 
كما تبين وجود فروق جوهرية بينهما فى المتغيرات الذهنية والعدوانية، واسإليب التفكير الاجرامى، واحداث الحياة الثاقة، والمخاطرة غير المحسوبة، والمجاورة الاجتماعية،

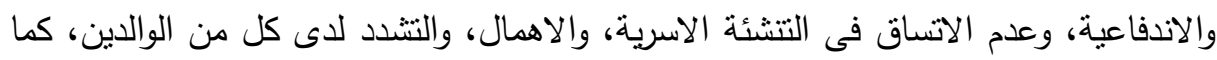

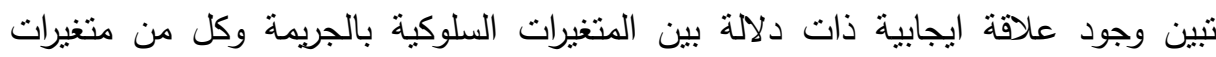
العدوانية والذهنية والاندفاعية، واسإليب التفكير الاجرامى، واحداث الحياة المثيرة للمشقة (الهام

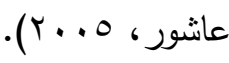

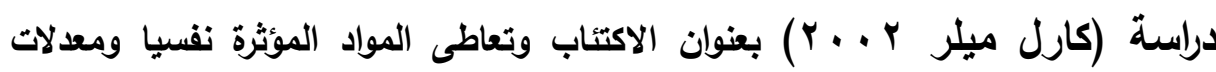
الانقطاع والانتكاسة، تهدف الى فحص العلاقة بين الاضطراب الاكتئابى، والاعتماد على المواد المؤثرة نفسيا وعلاقة معاودة النوبات الاكتئابية بحدوث الانتكاسة والعودة للتعاطى وتكونت عينة الدراسة من •rO مريض بوحدة علاج الادمان، ممن يتعاطى الكوكايين والهيروين والخمور، وقد تم استخدام المقابلة المقننة لتتخيص الاضطرابات النفسية واضطرابات سوء استعمال المواد المؤثرة نفسيا، وفقا لدليل التشخيص الاحصائى الرابع ل اضطرابات العقلية. وكشفت النتائج عن ان المرضى، الذين يعانون من اضطراب اكتئابى شديد، كانو اقل

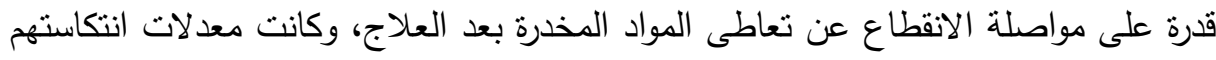
اعلى، مما يثير الى ان حدوث نوبات اكتئابية يعجل بحدوث الانتكاسة، ممايستلزم علاج هذه

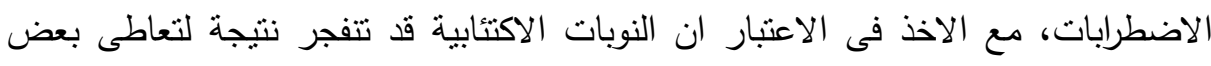

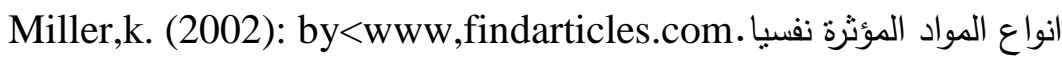
دراسة (افراح صالح الشمرى، 1 ( ـ ب) تهدف الدراسة الى التعرف على طبيعة العلاقة بين متغيرات الدراسة ومستوى الانجاز لاى الطلاب فى المجموعتين، والتعرف على الفروق واتجاهاتها ومدى دلالتها فى المجموعتين (فائقى الانجاز ومنخفضى الانجاز ) فى مجال دافعية الانجاز وبعض سمات الثخصية والمناخ الاسرى، ووضع مؤشرات تساعد العاملين فى مجال الارشاد النفسى التزبوى لتوفير مناخ يساعد طلاب المرحلة الثانوية على زيادة فاعلية الانجاز

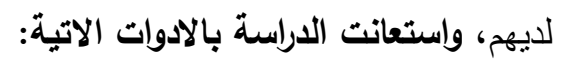




$$
\text { 1-مقياس سمات الثخصية (بى، اف } 7 \text { 1). }
$$

r-اختبار الدافع الانجاز للاطفال والراثندين (فاروق عبدالفتاح). r-مقياس المناخ الاسرى (علاء كفافى).

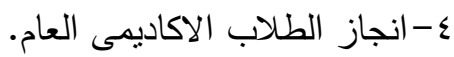

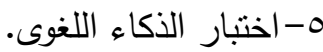

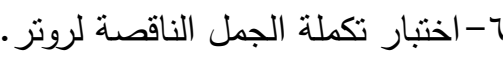

\section{اعتمدت هذه الدراسة على المنهج الوصفى، وتوصلت الى النتائج الاتية:}

ه توجد فروق دالة احصائيا بين منوسطات درجات الطلاب مرتفعى الاتجاز ودرجات

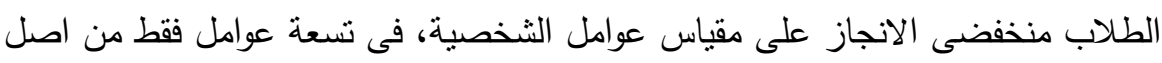

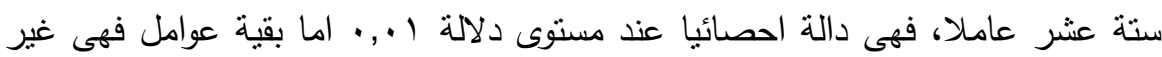
دالة احصائيا.

توجد فروق دالة احصائيا عند معظم الابعاد مقياس المناخ الاسرى والدرجة الكلية للمقياس داس دان عند مستوى دلالة ا.,., بين متوسطات الطلاب مرتفعى الانجاز ومنخفضى الانجاز

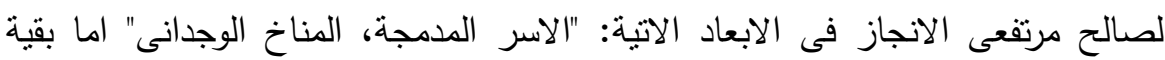

$$
\text { الابعاد فهى غير دالة احصائيا. }
$$

توجد فروق دالة احصائيا بين درجة الدافعية ومستوى انجاز الطلاب (مرتفع، منخفض)

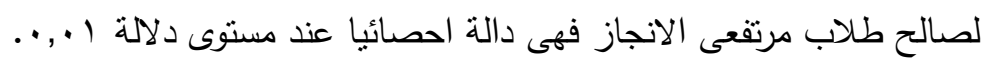

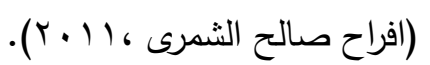

التعليق على الدارات السابقة : تتاولت الدراسات السابقة العديد من جوانب المشكلة اسباب المشكلة وبيئية واجتماعية ونفسية وخرج الباحث بعد الاطلاع على هذه الدراسات بالآتى:

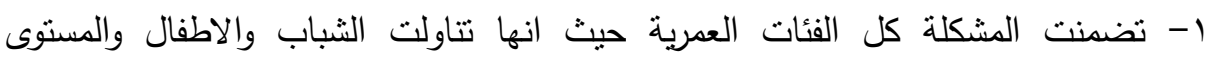
الاقتصادى حيث تضمنت ذات المستوى المخفض وذات المستوى المرتفع. r- كما تضمنت ايضا اوقات الفراغ احد الاسباب التى تؤدى الى تعاطى المواد المخدرة وايضا رفقاء السوء وايضا المشكلات التى تتعلق بالتفكك الاسرى. 
r- وأيضاً تضمنت المناهج المستخدمه حيث بعض الدراسات استخدمت المنهج الوصفى التحليلى وبعضها استخدم المنهج التجريبى والبعض الاخر استخدم المنهج الانثروبولوجى وايضا منهج المسح الاجتماعى وادوات جمع البيانات تعددت منها المقابلة والملاحظه والاستنيان وايضا تعددت المقاييس. ع- رغم هذا الكم الكبير من الدراسات السابقة الا ان الظاهرة مستمرة فى الانتشار مما تطلب

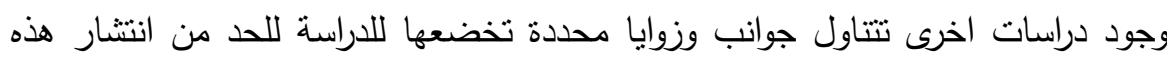
الظاهرة.

0- اختلفت متغيرات الدراسة الحالية عن الدراسات السابقة حيث انها تتتاول العوامل البيئية الفيزيقية والاجتماعية معا وايضا سمات الثخصية وتاثيرهم على الانتكاسة.

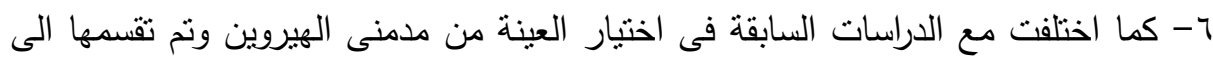
مجموعتين احتاهما من المنتكسين والاخرى من غير المنتكسين.

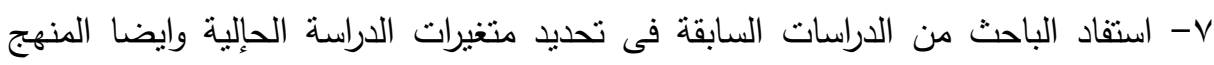
المستخدم وادوات جمع البيانات والمقاييس. ᄉ- اتفقت الدراسة الحالية مع العديد من الدراسات السابقة فى اختيار المنهج الارتباطى.

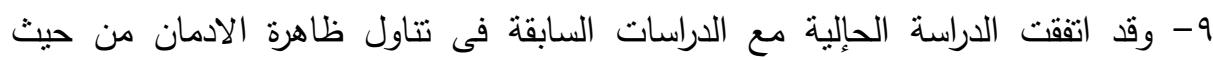
النعاطى والانتكاسة على الناحية السيكولوجية . • ا- اتفقت الدراسة الحإلية مع الدراسات السابقة من حيث الهمية نتاول ظاهرة ادمان

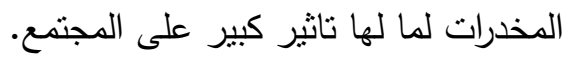
11- اوضحت الدراسات السابقة للباحث اهمية نتاول ظاهرة الادمان بصورة كلية من حيث تتاول تاريخها التطورى، ( التجريب - التعاطى - الادمان - التعافى - التعافى والمتابعة لعدم الانتكاسة ) او من حيث شمولية تتاول الفرد المدمن والمحيطين به، من لهن اسرة ومدرسة واعلام ومجتمع متكامل. 


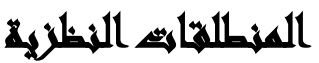

النظرية البيولوجية: مخ الانسان يحتوى على مواد كيميائية نقوم بنقل الاشارات المنبهة من خلية عصبية الى اخرى، ويعتبر الدوبامين والنورادرينإلين والسيروتونين واستيل كولين من اهم الموصلات الموجودة فى المخ، وتخزن هذه الموصلات فى الحويصلات الموجودة فى المناطق الملامسة لمحور الخلية العصبية بخلية اخرى، ويتم التتبيه بين الخلايا عندما تتكون شحنة

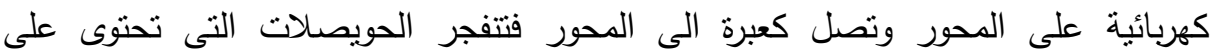
الموصلات فتتدفق فى فجوة الثباك ثم تلتصق بمستقبلات الخلية ويؤدى ذلك الى تتشيط شجيرات الخلية كهربائيا، فنتطلق الثحنة الكهربائية الى محور الخلية ونتكرر نفس العطلية ل التبييه خلايا ثالثة وهكذا.

حيث تقوم هذه الخلايا العصبية بصنع هذه الموصلات من مواد مشتقة من البروتينات التى تم تتاولها فى الطعام ومعظمها احماض امينية وذللك بواسطة خمائر خاصة نم تخزينها فى الحويصلات وتوجد ايضا خمائر تقوم بتكسر هذه الموصلات بعد ان تئدى وظيفتها، ويعاد امتصاصها مرة ثانية فى محور الخلية، ويتفاعل مخدر الهيروين مع هذه الموصلات بصورة او باخرى بحيث تختل وظائفها.

وحيث ان بعض الاحماض الامينية فى مخ الانسان لها تركيبا مقاربا للمورفين وله خواص فسيولوجية مشابهة او تفوق المورفين وسميت تلك المواد بالاندومورفين وعند تعرض الشعيرات العصبية الموجودة بالمخ الى جرعات منكررة من مخدر الهيروين فان الخلايا التى تتتج الاندومورفين تتوقف عن الاتتاج ويعتمد الجسم على جرعات الهيروين الخارجية بقيام وظائف تلك المادة العصبية وعلى هذا فانه عند توقف التعاطى لهذه المواد الخارجية فان الجسم يصاب بحالة شلل واضطراب فى الوظائف العصبية. وهناك بعض الافراد يكون عندهم نقص تكوينى فى قدرتهم على تكوين مادة الاندومورفين

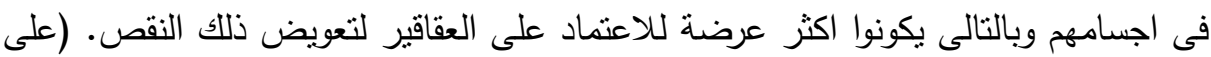

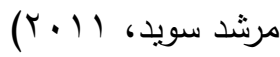


نظرية التحليل النفسى: تذهب نظرية التحليل النفسى الى ان المدمن تظهر عليه السلبية، والاتكالية، وعدم القدرة على تحمل التوتز النفسى، والالم، والاحباط، اى عدم نضوج الثخصية لهـية بوجه عام، وذلك لان الخمر او العقاقير وسيلة علاج ذاتى يلجأ إليها الثخص كما يرى الثى

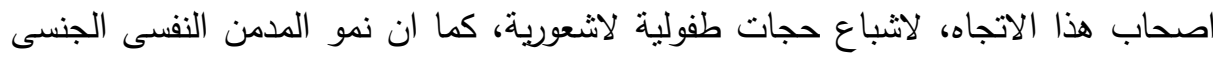

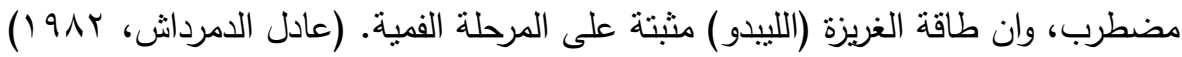
ومن زاوية اخرى تذهب هذه النظرية الى ان مدمنى المواد المخدرة هو شخص قد عانى فى طفولته ولم يستطيع التخلص من عقدة الطفولة (اوديب) عند الولد (عقدة إليكثرا) عند البنت، كما ان بعض المدمنين ضعيفى الانا اى انه ضعيف الثخصية، وسهل التاثير عليه، وعزيمته فاترة، وذلك هو الذى يجعله فريسة للمخدرات عن طريق التبعية لاصدقائه. (عفاف

$$
\text { محمد عبد المنعم، V... (Y) }
$$

كما يرى الفريد ادلر ان الذين يفشلون فى حياتهم كامدمنى المواد المخدرة او غيرهم انما يفتلون لافتقارهم الثعور بالود، والمحبة نحو الاخرين، وان الثخص المدمن هو شخص لديه

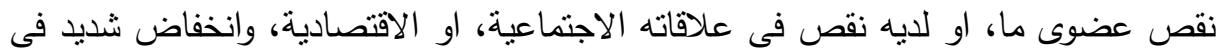
تقديره لذات بدون العقار ، ويعانى من الاكتئاب (سيد محمد عنيم، 9 (1) ). أى أن نظرية التحيل النفسى تقوم فى تفسيرها لعملية الادمان على أساسين:

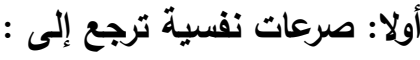
ا: الحاجة إلى الاشباع الجنسى النرجسى الذى يرجع اساسا الى اضطراب على علاقات الحب والاشثباع العضوى بخاصة فى المرحلة الفمية.

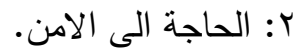
r: الحاجة الى اثبات الذات وتاكيدها. وتكرار التعاطى معناه الفشل فى حل تلك الصراعات واثشباع هذه الحاجات. الثانى: الآثار الكيميائية للمخدر: وهو الذى يميز مدمنى المواد المخدرة عن غيرهم، وبذلك

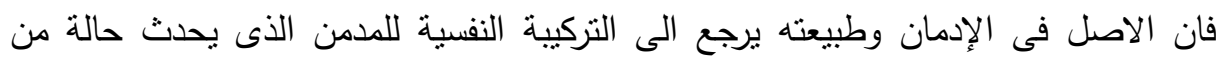

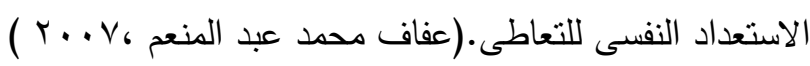


نظرية المشقة أو الضغوط: تتأسس هذه النظرية على قدرة البيئة الفيزيقية على فرض الضغوط على البشر، وتحدث الضغوط البيئية على الفرد عندما يصبح العبء البيئى الذى يمر به الفرد مرتفعا جدا او منخفضا جدا لفترات ممتدة من الزمن، وتحدث الضغوط البيئية عندما لاتتلاءم المنطلبات التى تفرضها البيئة على البشر مع قدرتهم على مواجهتها، ويمكن

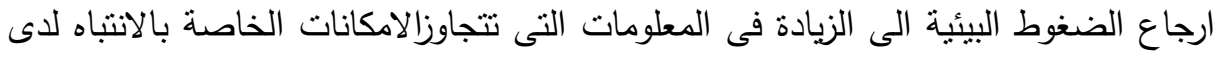
الفرد، وينتج هذا فى شكل اجهاد عقلى او نفسى يمكن ان تكون له مترتبات جسمية، وفى لهى احيان اخرى يكون رد الفعل للضغوط عبارة عن استجابة لعدم امكانية التنبؤ وعدم امكانية السيطرة المدركة للبيئة، والتى تترك الثخص يشعر بالعجز وعدم القدرة على مواجهة المواقف او التعايش معه. كما يمكن ان تؤدى هذه الضغوط الى حدوث امراض عضوية تتراوح بين

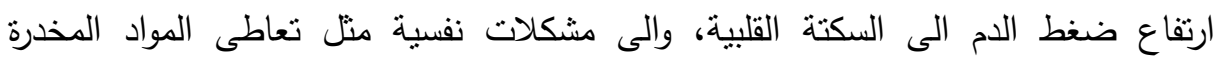
والاكتئاب واضطرابات الثخصية، ويوجد ما يؤيد هذه النظرية حيث نتين ان الضغوط ولئ يمكن

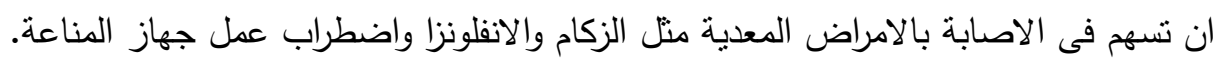

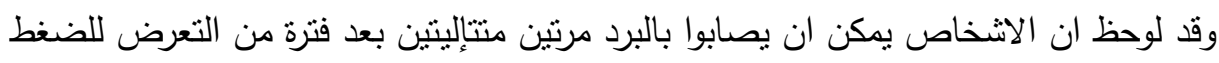

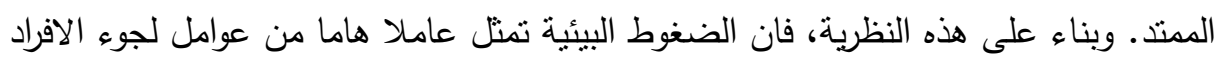
الى ادمان المواد المخدرة، كما انها تفسر ايضا الاصنابة بالعديد من الامراض. (جمعة سيد

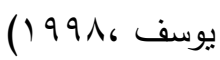

\section{مينم الصواسما}

بلغت عينة الدراسة بصورتها النهائية ـ0 شخص من مدمنى مخدر الهيروين مقسمة الى

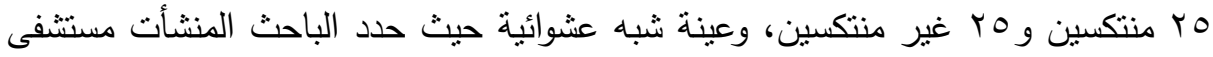
الدمرداش لتمثل الحكومية ومستشفى ابوالعزايم لتمثل الخاصة والتى تخدم مرضى الادمان من وعن

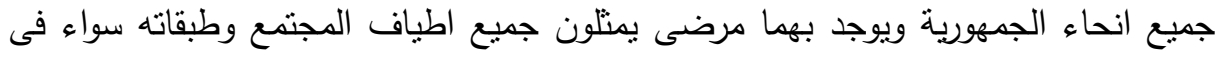
العلاج الاقتصادى او المتميز • 


\section{شروط العينة: - مانة}

ا - تم اختيار العينة من المدمنين على مخدر الهيروين. r - أن يكون المدمن قد تجاوز مرحلة انسحاب المخدر من الجسم وان كانت حوالى اسبوع كان الباحث يختار من تجاوزت فترت دخوله المستثفى اسبوعين على الأقل. r - أن يكون السن بين \1 و ـ0 سنة لتمثل كل الاعمار من الراشدين تقريبا.

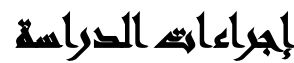

أدوات جمع البيانات: اعتمد الباحثون في البحث على المادة العلمية النظرية والميدانية ومصادرهما ما يلي:

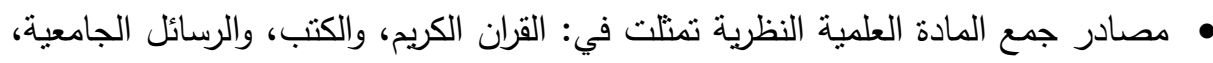
والمقالات، والقرارات والمراسيم القانونية، والقواميس والمعاجم، والإنترنت.

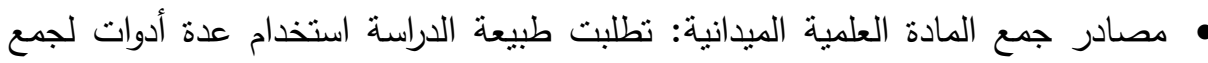

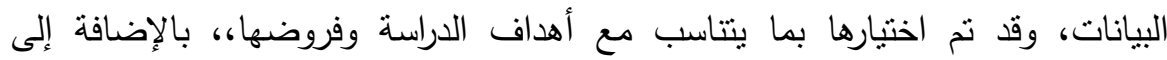

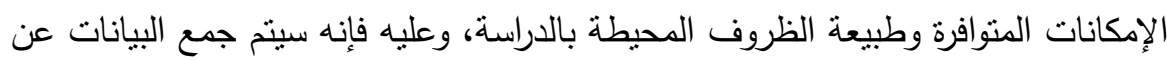
طريق: (استنيان العوامل البيئية، ومقياس ايزنك للثخصية). ويتم اختيار هذه الأدوات على ضوء أسس علمية، للوصول إلى البيانات المطلوبة، وبالتالي تحقيق أهداف البحث. أولاً: الثبات: استبيان العوامل البيئية: نم تصميم الاستبيان لمعرفة اثر العوامل البيئية على مدمن مخدر الهيروين وهل هنالك علاقة ام لا. وقد تم بناء هذا الاستبيان على خمسة أبعاد:

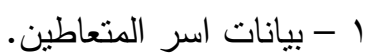
r - بيانات لمعرفة ظروف وخبرات التعاطى. r - بيانات حول الصورة الذهنية الثائعة تجاه تعاطى وادمان المخدرات. ع - بيانات حول السياق الفيزيقى. 
وقام الباحث بالاطلاع على عدد من المقاييس والاستبيانات ذات الصلة بابعاد الاستبيان

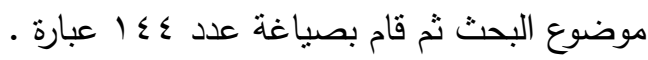
تم قبوله قيم معاملات الثبات لأبعاد استبيان العوامل البيئية جميعها حيث بلغت فئ قيم

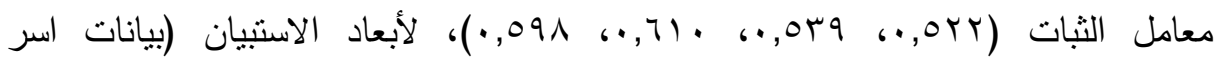
المتعاطين، تبلا بيانات لمعرفة ظروف وخبرات التعاطى، بيانات حول الصورة الذهنية الثائعة

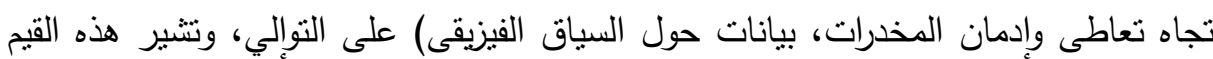

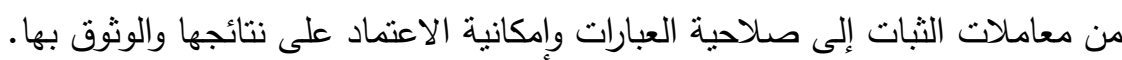

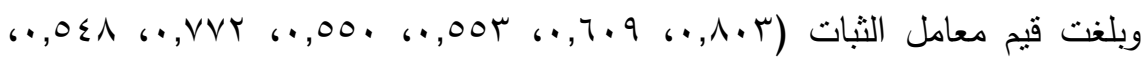

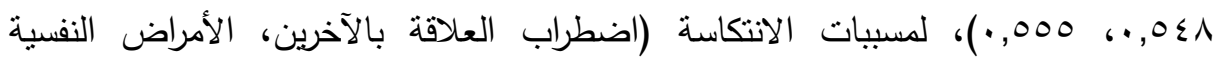

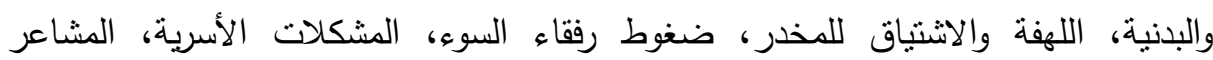
المصاحبة للتعاطى (المشاعر السارة)، المشاعر المصاحبة للتعاطى (المشاعر الغير السارة))

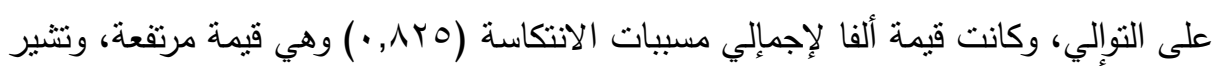

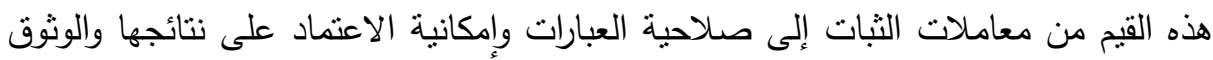

كما نم قبول معاملات ثبات العبارات لأبعاد قائمة إيزنك جميعها حيث بلغت قيم معامل

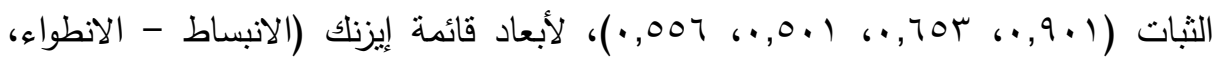

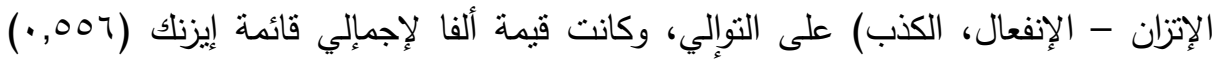
وهي قيمة مقبولة، ونتير هذه القيم من معاملات الثبات إلى صلاحية العبارات وإمكانية

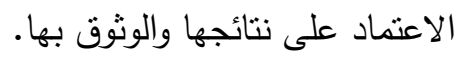
ثانياً: الصدق: صدق الاتساق الداخلي السابق لأبعاد استبيان العوامل البيئية نجد أن معامل

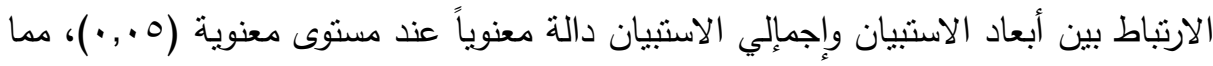

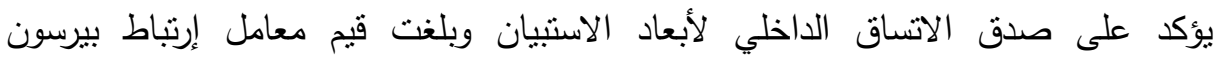

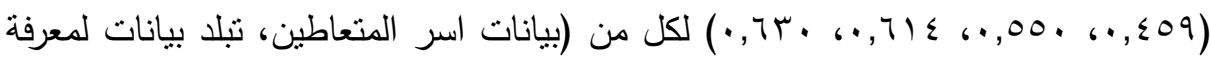

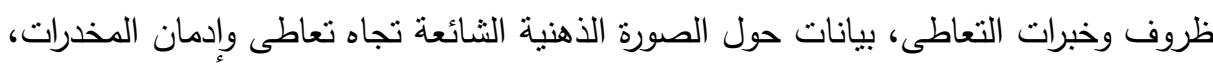

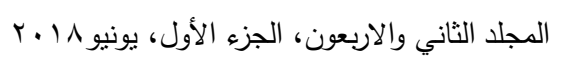


بيانات حول السياق الفيزيقى) على التوإلي، وللمزيد من التحليل قام الباحث بحساب معامل

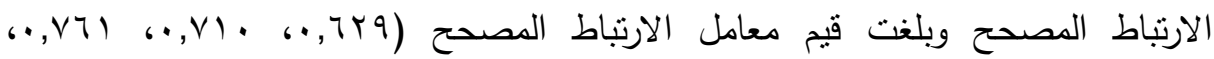

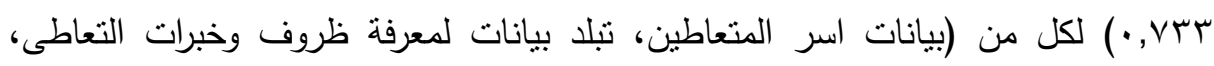

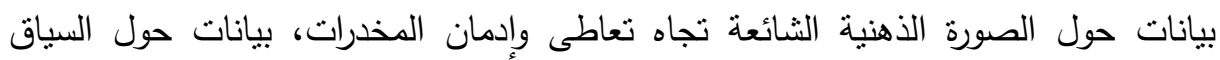

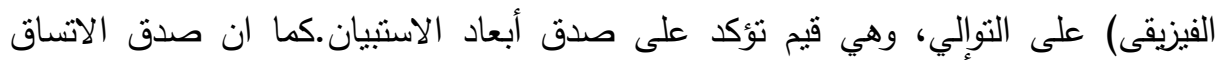

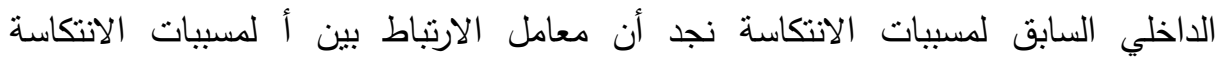

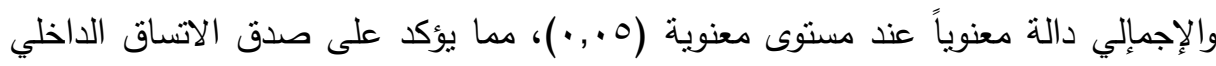

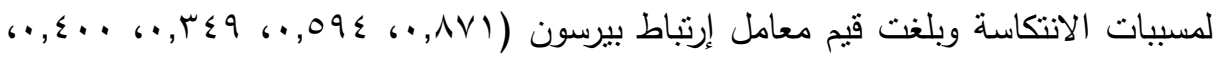

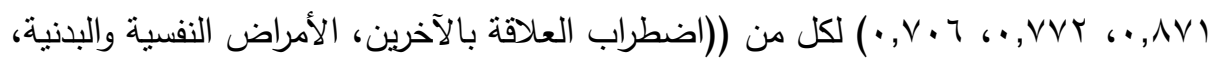

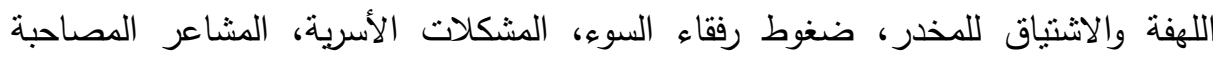

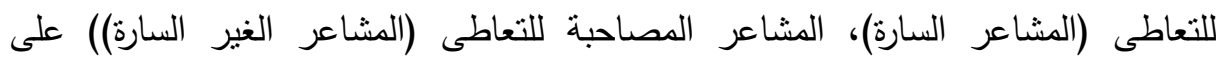
التوإلي، وللمزيد من التحليل قام الباحث بحساب معامل الارتباط المصحح وبلغت قيم معامل

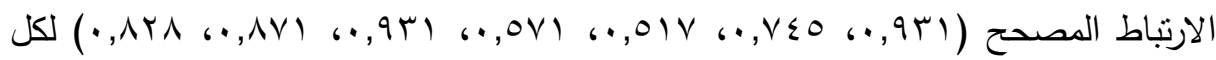

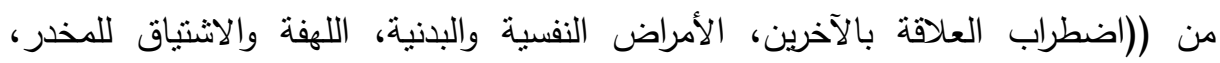
ضغوط رفقاء السوء، المشكلات الأسرية، المشاعر المصاحبة للتعاطى (المشاعر السارة)،

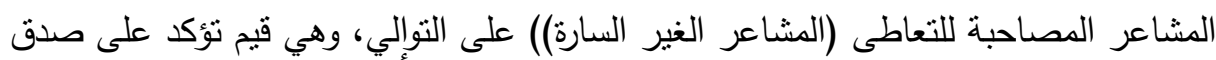

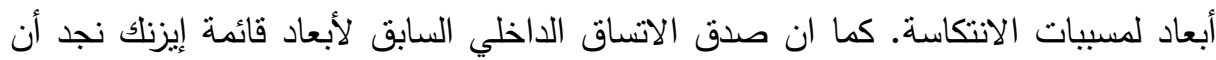

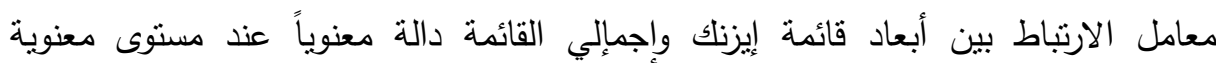

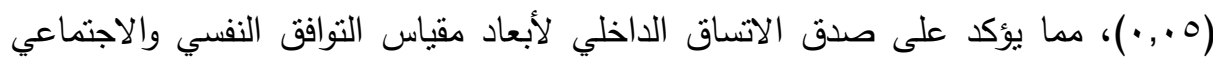

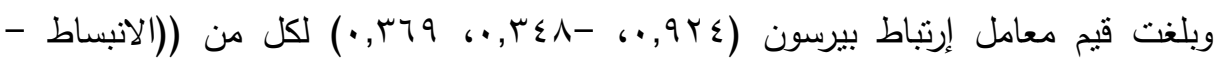

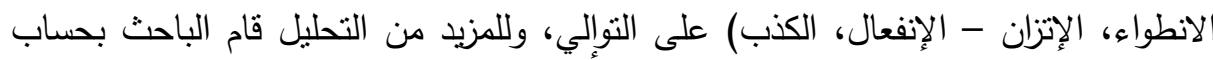

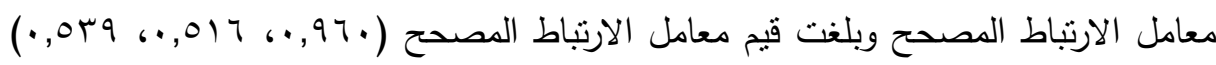
لكل من (الانبساط - الانطواء، الإتزان - الإنفعال، الكذب)، وهي قيم تؤكد على صلاطئ صدق أبعاد قائمة إيزنك. 


\section{نئائي السراسة وهنالجمتهما}

الفرض الأول: توجد علاقة ذات دلالة إحصائية بين سمات الثخصية وعودة مدمن للهيروين.

جدول(1): توزيع عينة الدراسة تبعاً للسمات الثخصية (الانبساط - الإنطواء)

\begin{tabular}{|c|c|c|c|c|c|c|c|c|}
\hline \multirow{2}{*}{ المعنوية } & \multirow{2}{*}{ معامل } & \multicolumn{2}{|c|}{ الإجمإلى } & \multicolumn{2}{|c|}{ غير المنتكسين } & \multicolumn{2}{|c|}{ المنتكسين } & \multirow{2}{*}{ قائمة إيزتك } \\
\hline & & النسبة & العدد & النسبة & العدد & النسبة & العدد & \\
\hline \multirow{5}{*}{$\cdot, \cdot r$} & \multirow{5}{*}{$r, r, r$} & \%ఛร,. & IT & $\% \varepsilon \leqslant,$. & 11 & $\% \varepsilon, \cdot$ & 1 & الانبساط- الاتزان \\
\hline & & $\% 17$, & rA & $\% \backslash r,$. & $r$ & \%०r,. & $\pi$ & الانبساط - الانفعال \\
\hline & & $\% \backslash \wedge$, & 9 & \%rr, & $\Lambda$ & $\%\{, \cdot$ & 1 & الانطواء - الاتزان \\
\hline & & \%Үч, & $\pi$ & $\% \backslash r, \cdot$ & $r$ & $\% \varepsilon,$, & 1. & الانطواء - الانفعال \\
\hline & & $\% 1 \ldots$ & 0. & $1 \ldots$ & ro & $1 \ldots$ & ro & إجمالي قائمة إيزنك \\
\hline
\end{tabular}

يتبين من الجدول رقم (1) وجود علاقة ارتباطية بين السمات الثخصية ( الاتزان والانبساط، الانفعال والانبساط، الاتزان والانطواء، الانفعال و الانطواء ) وعودة الدمن

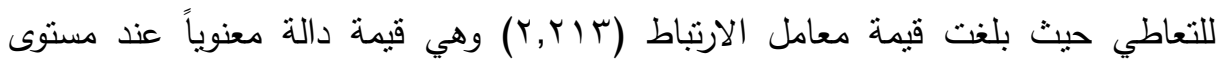
معنوية (0. , •).

يثتث صحة الفرض حيث توجد علاقة ارتباطية ذات دلالة احصاية بين عينة الدراسة(المنتكسين وغير المنتكسين ) من حيث سمات الثخصية وعودة مدمن الهيروين •للتعاطى

حيث نم تقسيم العينة الى مجموعتين كما تم تقسيم كل مجموعة الى اربعة مجموعات (أ، ب، ج، د د ) و وكانت كالآتي: بحيث تم تقسيم المجموعة الاولى ( المنتكسين ) إلى الى أ : الانبساط والاتزان ب ) الانبساط والانفعال ج ) الانطواء والاتزان د ) الانطواء والانفعال

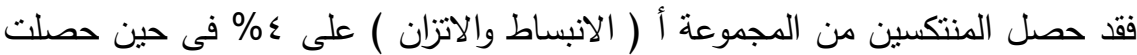
المجموعة ب ( الانبساط والانفعال ) على هor\%، كما حصلت المجوعة ج (الانطواء والاتزان)

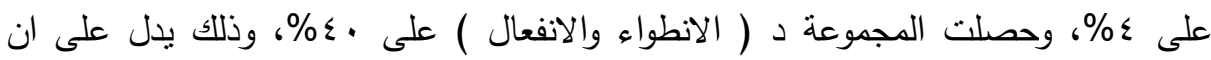

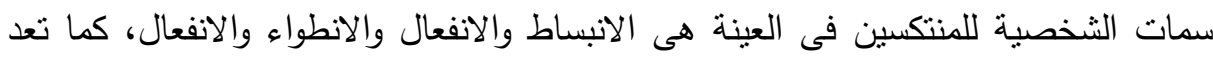


سمة الانفعال هى السائدة فى سمات الثخصية للمنتكسين وهى تؤثر على عودة المدمن كمان للتعاطى.

\section{كما تم تقسيم المجموعة الثانية ( غير المنتكسين ) إلي:}

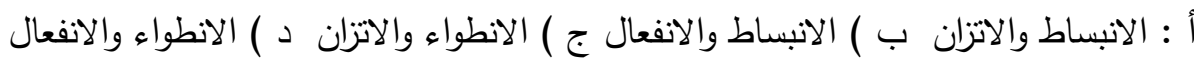

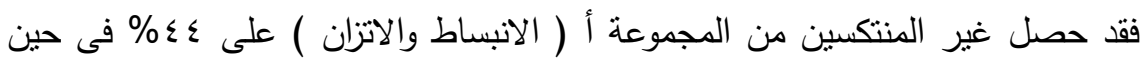

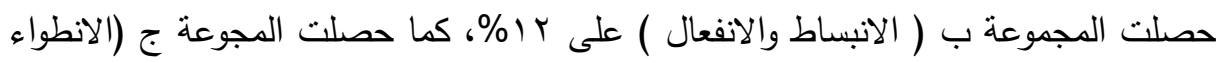

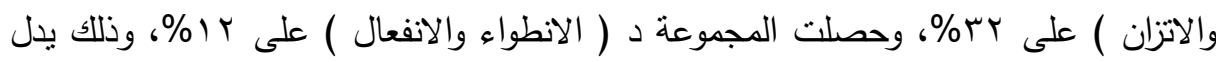
على ان سمات الثخصية لغير المنتكسين فى العينة هى الانبساط والاتزان والانطواء والاتزان،

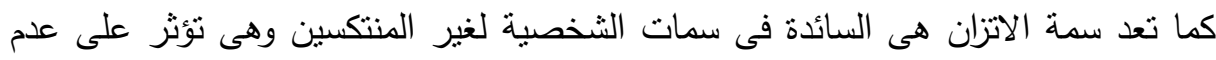
عودة المدمن للتعاطى.

اتفقت نتائج الفرض مع نظرية سمات الثخصية حيث تعتبر نظرية السمات من بين النظريات التى لها تاثير ودور كبيرين فى تحليل الثخصية ـ ـوعلى وفق منظورها، تميز خواص الثخصية وتحدد سلوك الفرد طبقا لقياس الصفات الثخصية لديه، تقترض هذه ونه النظرية بان الاستجابات المختلفة للفرد فى المواقف الخاصة نستتد الى الاستعدادات المحددة المتوفرة لديه ـ وتطلق على هذه الاستعدادات الصفات الفردية، اى بعبارة اخرى، انه بالامكان

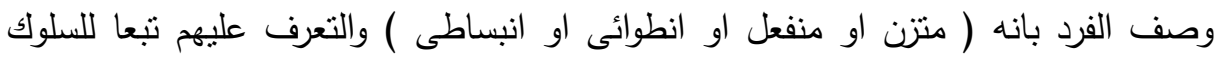

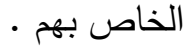
كما اتفقت نتائج الفرض مع نظرية تحليل العلاقات التبادلية لعالم الامريكى اريك بيرن وهى أن كل انسان لديه تلاث حالات للذات يتصرف من خلالها الفرد وهى ( ذات الوالدية، وذات الطفولية، وذات البالغ )، كما تمنل ذات البالغ فى ( الموضوعية - المنطق ). وهى تعنى الفرد الأى يتميز بالصفات التالية:

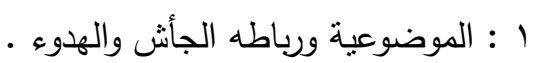
r : تجميع وتحليل المعلومات لحل المشكلات واتخاذ القرارات بموضوعية . r : لاتحكم تصرفاته العاطفه والمشاعر • 
وتبدأ حالة ذات البالغ من • ا شهور وتشتمر الى نهاية العمر .

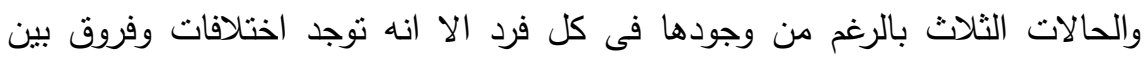
الافراد فالبعض يغلب عليه وتصرفات احدى الذوات الاخرى ويسمى فى هذه الحاله حالة تضخم الذات ـ ومن ذلك يتضح ان المدمن الذى لديه حالة ذات البالغ هى السائدة يصبح لديه الاتزان وهو ما يتفق مع نتائج الدراسة .

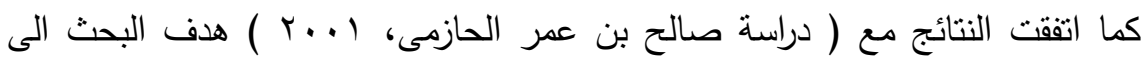
معرفة اثار تعاطى المخدرات وعلاقته بابعاد الثخصية وبعض المتغيرات الاسرية فى المجتمع السعودى • وتوصلت الدراسة الى وجود فروق ذات دلالة احصائية فى ابعاد الثخصية بين مدمنى (المهئات- المنبهات)، ووجود فروق دالة فى معظم ابعاد الثخصية بين مدمنى المواد

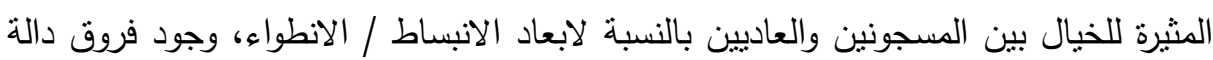
احصائيا فى معظم ابعاد الثخصية بالنسبة للمقياس الاول لايزنك بين مدمن المنشطات لابعاد الابسات

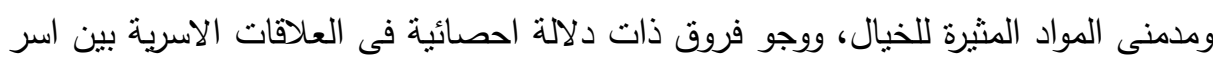

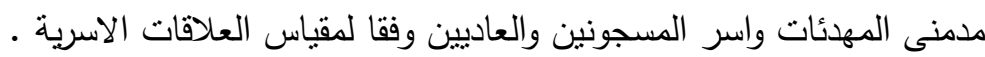
الفرض الثاني: توجد فروق ذات دلالة إحصائية بين عينة الدراسة (المنتكسين وغير المنتكسين) لسمات الثخصية. جدول(ץ): اختبار ت لتوضيح الفروق الإحصائية بين عينة الدراسة لاختبار إيزنك للسمات الثخصية

\begin{tabular}{|c|c|c|c|c|c|c|}
\hline \multirow{2}{*}{ مستوي } & \multirow{2}{*}{ "تيمة } & \multicolumn{2}{|c|}{ غير المنتكسين } & \multicolumn{2}{|c|}{ المنتكسين (ن= ه Y) } & \multirow{2}{*}{ الأبعـاد } \\
\hline & & المُعياري & الحسابي & المعياري & الحسابي & \\
\hline$\cdot, \Gamma$ & I, & $r, 00$ & $1 \varepsilon, O Y$ & 0,04 & $1 \mu, \cdot \varepsilon$ & الانبساط - الانطواء \\
\hline$\cdot, \ldots 1$ & 7,790 & $r, 9 r$ & $11, V Y$ & $r, 00$ & $1 \wedge, \wedge$. & الإنزان - الإنفعال \\
\hline$\cdot, \cdot r$ & $Y, \leqslant 07$ & $\cdot, r v$ & $1, \wedge \varepsilon$ & $\cdot, V T$ & Y,YY & الكذب - الصدق \\
\hline$\cdot, \cdots$, & $\varepsilon, 779$ & $0, r q$ & $r 9,9 Y$ & $\varepsilon, \Gamma \mu$ & rד, זY & إجمالى قائمة إيزنكك \\
\hline
\end{tabular}


من الجدول السابق للفروق الإحصائية بين عينة الدراسة لاختبار إيزتك للسمات الثخصية يتبين الآتي:

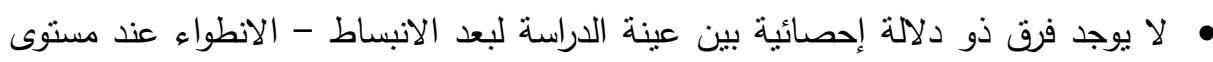

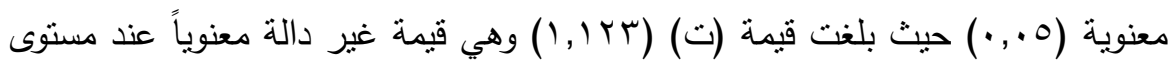

$$
\text { معنوية (0., (•). (0.0) }
$$

• يوجد فرق ذو دلالة إحصائية بين عينة الدراسة لبعد الإتزان - الإنفعال عند مسنوى معنوية

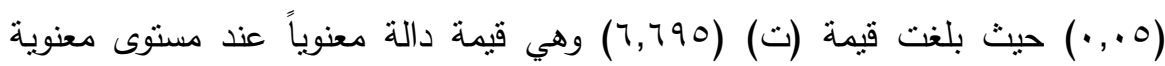
$\cdot(\cdot, \cdot 0)$

• يوجد فرق ذو دلالة إحصائية بين عينة الدراسة لبعد الكذب - الصدق عند مستوى معنوية

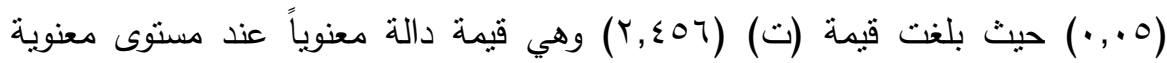
$\cdot(\cdot, \cdot 0)$ • يوجد فرق ذو دلالة إحصائية بين عينة الدراسة لإجمالإلي قائمة إيزنك عند مستوى معنوية

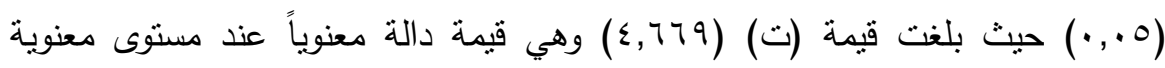
$\cdot(\cdot, \cdot 0)$

لذا يثبت صحة الفرض: نوجد فروق ذات دلالة إحصائية بين عينة الدراسة (المنتكسين وغير المنتكسين) لسمات الثخصية.

حيث توجد فروق ذات دلالة احصائية فى الصورة الذهنية بين عينة الدراسة

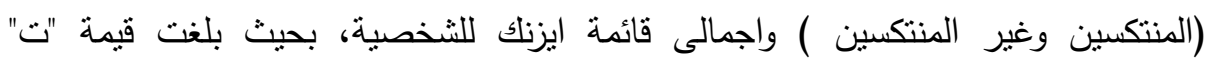

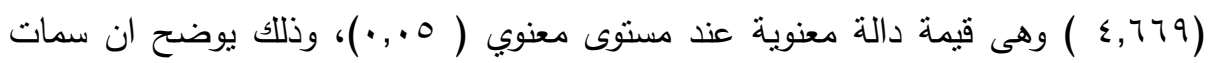

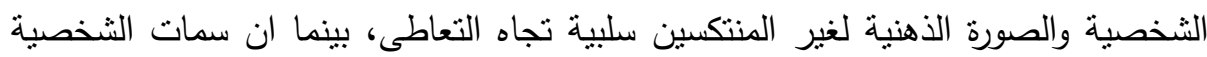
والصورة الذهنية للمنتكسين ايجابية تجاه التعاطى، اذا هناك فروق دالة احصائيا بين عينة الدراسة ( المنتكسين وغير المنتكسين ) لسمات الثخصية والصورة الذهنية تجاه التعاطى. 
كما اتفقت نتائج الفرض مع نظرية انماط الثخصية حيث اشار ايزنك الى ان اكثر

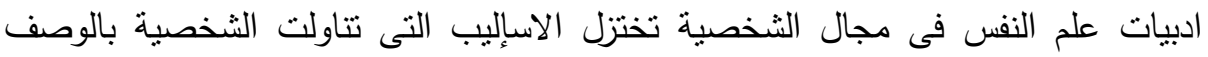
والثقويم، وتركز على نظريتى الانماط والسمات ـ وان العديد من نظريات الثخصية التى

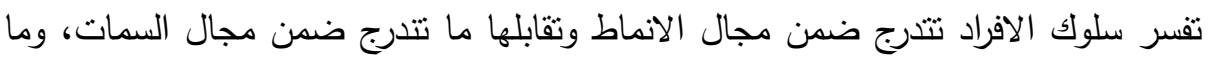

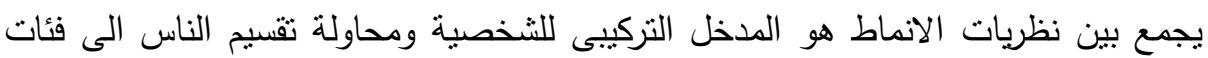

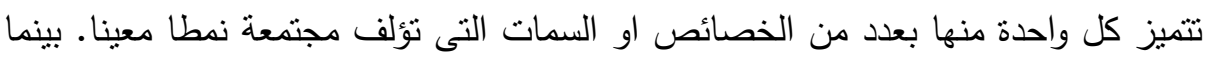
تشترك نظريات السمات فى المدخل التحليلى للثخصية وتوضع قائمة بالسمات التى تتكون منها الثخصية. كما اتفقت نتائج الفرض مع دراسة ( إيمان سعد احمد، I... الحالية الى معرفة العلاقة بين العلاقات الاسرية للمراهقين وبعض سمات الثخصية فى ضواء نظرية العوامل الخمس الكبر للشخصية، وتحقيقا لهذا الهذف اجريت الدراسة على عينة

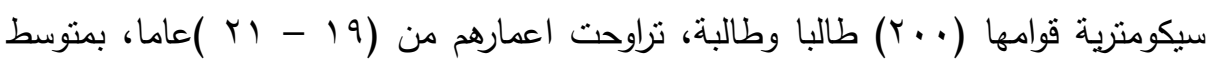

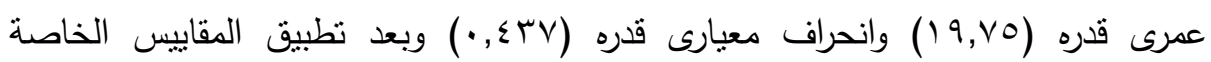
بالدراسة ( مقياس العلاقات الاسرية، ومقياس العوامل الخمسة الكبرى للشخصية ) اسفرث

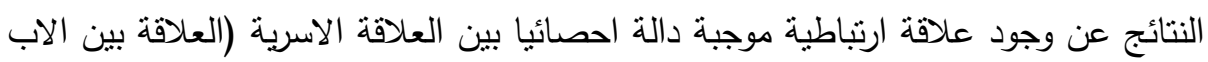

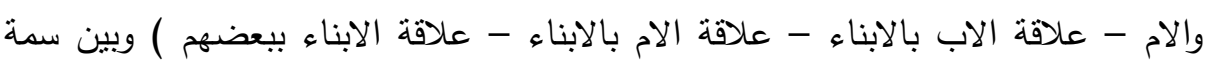

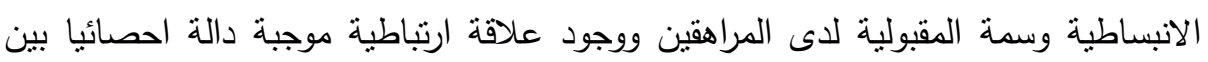

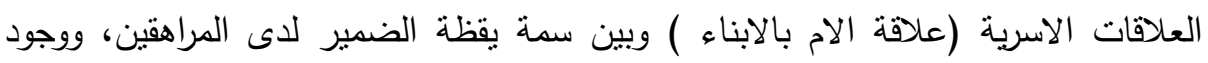

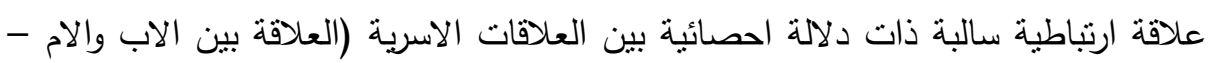

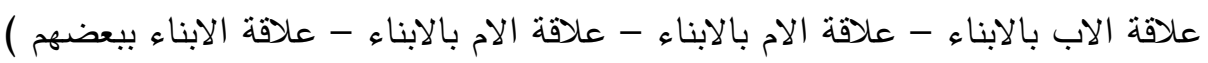
وبين سمة العصابية لدى المراهقين ،كما وجدت علاقة ارتباطية موجبة دالة احصائيا بين باهلاه

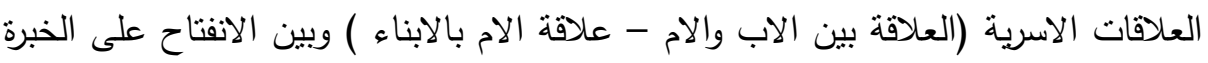

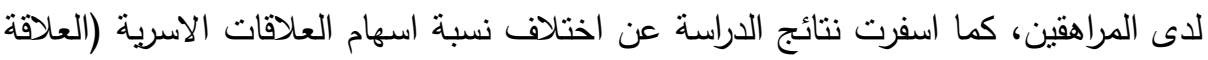

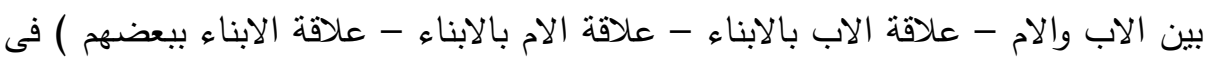

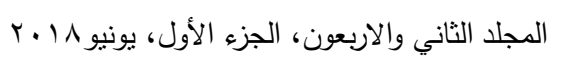


سمات الثخصية الخمسة الكبرى: حيث تسهم العلاقات الاسرية فى الانبساطية بنسبة (r (., •\%) فقط، وهى نسبة غير دالة، بينما تسهم العلاقات الاسرية فى سمة يقظة الضمير بنسبة (0\%\%) من التباين الكلى لعامل يقظة الضمير كاحدى سمات الثخصية بدلالة مقارنة

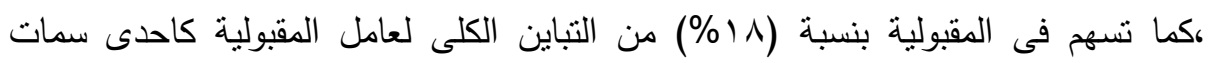

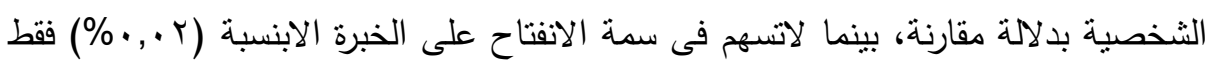

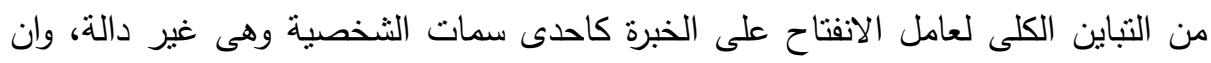
العلاقات الاسرية نسهم فى سمات الثخصية ككل لدى افراد العينة بنسبة (rr\%) من التباين الكلى لعامل سمات الثخصية بدلالة مقارنة ويعد متغير منبئ بعامل سمات الثخصية.

\section{تموسيامت الصواسلة}

• نظر الانتشار ظاهرة تعاطى وادمان المخدرات وتأثثرها على الامن القومى سلبا وبشدة

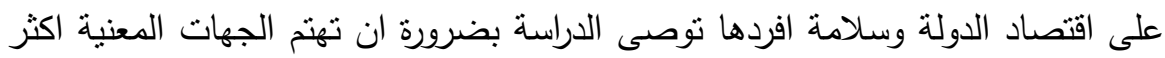
بهذه الظاهرة. • ضرورة أن تكون هناك برامج منقدمة لمكافحة المخدرات وان يلازم الاهتمام بخفض الطلب الاهتمام بخفض المعروض ومقاومة الاسإليب المخترعة من تجار المخدرات.

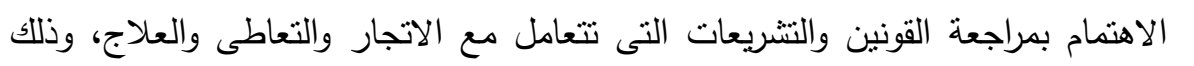
لتلافى الضعفالتشرعى فى عملية العلاج. • انثاء الدولة لعدد من المصحات المتخصصة فى العلاج والتأهيل وجذب الكوادر المحترفة

والمدربة إليها وعمل تدريب مستمر لرفع كفاءة العاملين على علاج متعاطى المخدرات.

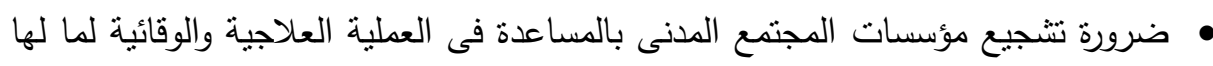
من خبرات ولقربها من المجمعات المحلية الصغيرة وسهولة التواصل معها من المدمنين وذويهم. • أهية توفير برامج علاجية مقننة ومدروسة ذات فاعلية وتعميمعا وتدريب العاملين بالمجال عليها ومراجعتها كل فترة. 
• ضرورة الإشراف على ما يقدمه الاعلام عن ظاهرة الادمان ومراجعته قبل عرضه لتجنب

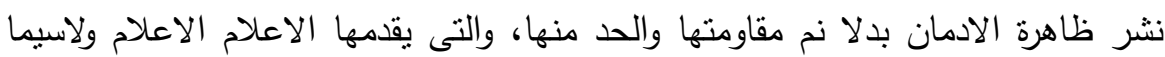
الدراما بصورة نساعد على زيادة عدد المدمنين وليس تقليلهم. ضرورة اتخاذ اللازم نحو الزام المدمن بالمتابعة مع العيادات الخارجية كثرط للعلاج

$$
\text { بمستشفيات الدولة. }
$$

ضرورة التوعية بالدفئ الاسرى للاباء ومن اجل حماية ابنائهم من اصدقاء السوء واللجوء

$$
\text { لتعاطى المخدرات ثم لادمان. }
$$

ه الاهتمام بالتوعية باضرار المخدرات فى سن مبكر والتوعية بكيفية اكتثاف المدمن مبكرا

$$
\text { للتعجيل بعلاجة. }
$$

الاهتمام بالنواحى النفسية لطلاب المدارس والجامعات والمراهقين خارج التعلم واكتشاف

$$
\text { الاعراض غير السوية وعلاجها حتى لايصبح الفرد فريسة للادمان. }
$$

ضرورة معالجة التفكلى الاسرى التى تعد احد الاسباب الهامة فى انتشار ظاهرة الادمان. ضرورة توفير الرعاية النفسية والاجتماعية للبيئات الفقيرة او المجتمعات المهمشة

$$
\text { والجماعات الهثة التى يسهل اختراقها من مروجى المخدرات. }
$$

ضرورة مواجهة المشكلات الاجتماعية والاقتصادية من خلال البرامج الحكومية وبرامج المجتمع المدنى اخذ فى الاعتبار اعادة تأهيل المدمن من حيث القدرة على مواجهة

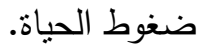

ضرورة الاهتمام بالرعاية النفسية والوقائية وتقديم الخدمة النفسية والاجتماعية التى تصل للمواطن فى مجتمعه المحلى الصغير وعدم نركز تقديم الخدمات على المدن الكبرى.

\section{المرالئ}

أحمد ابو الروس(1919 ()): مشكلة المخدرات والادمان، الاسكندرية المكتب الجامعى الحديث.

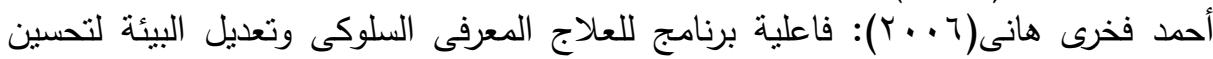

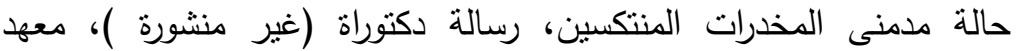
الدراسات والبحوث البيئية، جامعة عين شمس.

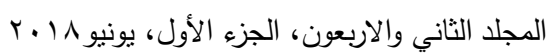




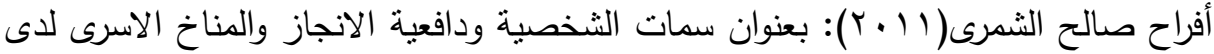

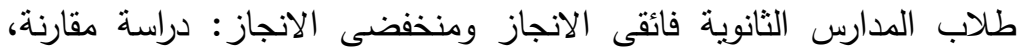

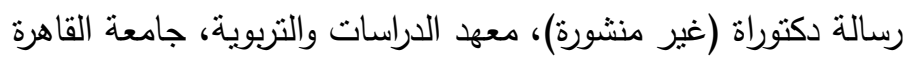

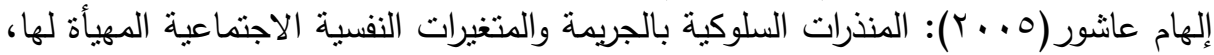

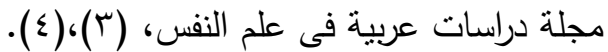
أمين ساعاتى( (99 ()): تبسيط كتابة البحث العلمى فلى من البكالوريوس والماجستير والدكتوراه،

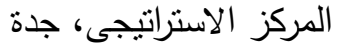

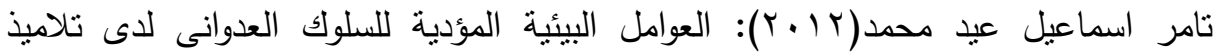

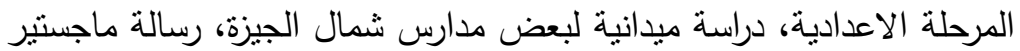

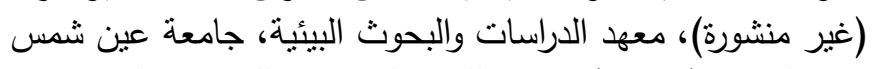
جمال ماضى ابو العزايم (911 ()): فى اللقاء الصحفى للمؤتثر العربى الاول لمكافحة

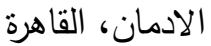

جمعة سيد يوسف(991 (1)): الوقاية من تعاطى المخدرات بين الواقع والمأمول، دراسة نفسية،

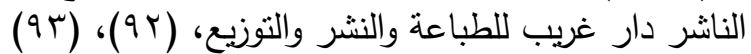

جودة سمير جوده محمد(ى ( ب)): نوعية الحياة وسمات الثخصية وعلاقتهما باعادة تأهيل

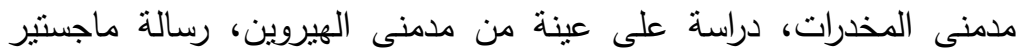

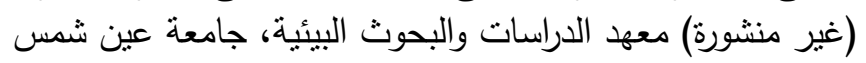

سيد محمد غنيم(9NV (1): سيكولوجية الثخصية محدداتها قياسها نظريتها، القاهرة، دار النهضة العربية

صفوت محمود درويش، ويسرى ياقوت(ب991): الهيروين دعوة الى الموت، الاسكندرية: مطابع جريدة السفير وبري

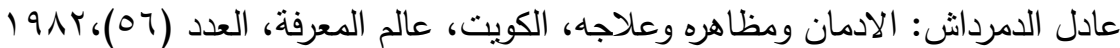

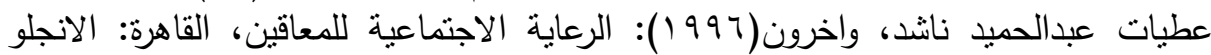

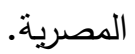

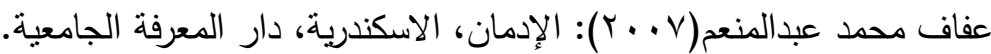

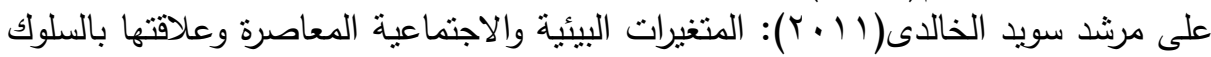

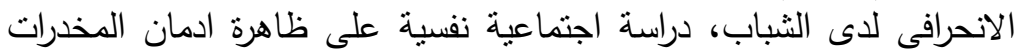

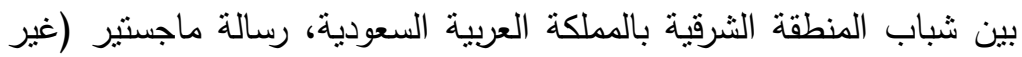

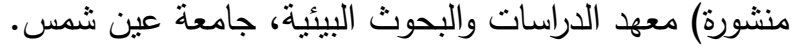
عماد السكاف (ך . . ץ): الانتكاسة، الرياض: وزارة الصحة مجمع الامل للصحة النفسية. 


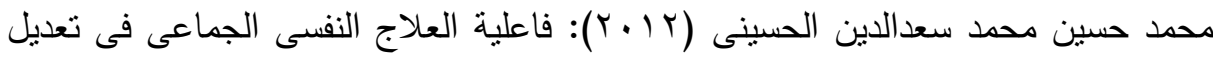

بعض المتغيرات النفسية لاى متعاطى المخدرات، رسالة دكنوراه (غير منشورة)

كلية الاداب، جامعة المنصورة.

محمد مدحت ابوبكر الصديق(1991): فاعلية العلاج الاسرى فى خدمة الفئنة الفرد فى علاج

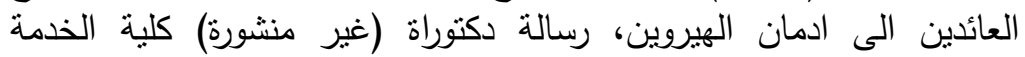

الاجتماعية، جامعة حلوان.

Kala, J. K (1999): Introduction to psychology. Belmont, California: Wadsworth.

Miller, K (2002) :Dyepression and substance use remission and relapse rates American Familphysician, by, www.findarticles.com.

Williams. Jills (2003): Depression, PSTD, substance abuse Increase in wake of september11 attacks research findings, vol17 ,No4. H. ttp.w.w.w nidannih.gov.

\title{
ENVIRONMENTAL FACTORS AND PERSONALITY \\ TRAITS AND ITS RELATIONSHIP TO THE RETURN \\ OF THE ADDICTED TO DRUGS \\ (A STUDY ON A SAMPLE OF HEROIN ADDICTS)
}

Karam Din, Leila, A. ${ }^{(1)}$; Shoman, A. E. A. ${ }^{(2)}$ and Ahmed, A. M. 1) College of Graduate Studies for Children, Ain Shams University

2) Faculty of Medicine, Ain Shams University.

\begin{abstract}
The study aims to identify the environmental factors personal characteristics in relation to the return of the addict to deal, the researchers used in the present search descriptive study; because they are designed to find out the influential factors in the phenomenon, and analysis of the process of interaction between the less descriptive of the
\end{abstract}

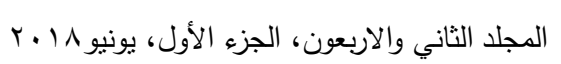


instrument, the presence of the theoretical heritage of previous studies that can support the theme of this research, which still needs many, many studies.

Researchers used a questionnaire tools of environmental factors and the eysenck have developed the curriculum used addressing for route flooding on personality; to achieve the objectives of the study, and on the basis of knowledge of the relationship between the variables of the study, with a view to access to know whether there is a relationship or not.

The sample is a single 50 is divided into 25 single detractors and 25 not reversible from the hospital Demerdash and hospital Abu azayem , The study has reached a set of conclusions, the most. important:

1- There is a statistically significant relation between personality traits and the return of the addict heroin use.

2- There is a statistically significant relation between common mental image toward dealing and personal characteristics.

Keywords: Environmental factors,. personality traits,. The setback. 